\title{
The Determinants of Domestic Air Passenger Demand in the Republic of South Africa
}

\author{
Mr Olebogeng Ambrocius Baikgaki \\ Dr. Olebogeng David Daw \\ Department of Economics, North West University, \\ Mafikeng, North West Province, South Africa \\ E-mail: Ambrosssb@yahoo.com, David.Daw@nwu.ac.za
}

\author{
Doi:10.5901/mjss.2013.v4n13p389
}

\begin{abstract}
Analysing air passenger market is an integral part of air transport industry and form part of corporate planning process. This paper seeks to assess the determinants of domestic air passenger demand in the Republic of South Africa. The methodology used involved collection of data for passenger movements in South Africa for the period 1971 - 2012 to determine the pattern of air travels. Data on macro and micro-economic variables considered to affect demand for air passenger travel were also collected. Multiple regression method was then used to develop models of demand in respect of air passenger movement. An attempt was made to develop models for domestic air passenger travel demand in the country with different combinations of explanatory variables utilising a stepwise regression technique. The model, which has the total consumption, population size, airfares and oil prices as the explanatory variables, is the most appropriate model to represent the demand for domestic air passenger travel in South Africa. The rest of the models discussed suffer from multicollinearity. The model selected may be used to identify and measure the relations between domestic air passenger demand and the economic and demographic factors in South Africa.
\end{abstract}

Keywords: Regression analysis; Domestic air passenger demand; Socio-economic variables, South Africa

\section{Introduction}

Analysing and estimating the current and future demand for an organisation's product and services is a key element in planning its operations. The transport industry comprises of intensive competition, it is therefore appropriate to conduct demand analysis of every mode of transport (Aderamo, 2010). Air transport, just like any other mode of travel, plays a crucial role in the economy of a country due to its catalytical character to economic activities. It provides a necessary supporting role to international, regional and local prosperity and economic growth. It also enhances the quality of life by improving access to jobs, education, health care, markets as well as social and leisure activities (SAGIC $\left.{ }^{1}, 2013\right)$.

Air transport provides world-wide transportation network, which makes it essential for making business globally as well as enhancing tourism (ATAG, 2007). Management of air transport industry make decisions about current and future development within the industry. These include activities such as airport development plans, investment decisions and labour high or shedding. Plans cannot be properly carried out without knowing the level of demand for the service provided and the determinant thereof (Wells, 2003). Worldwide, air transport mode is transporting two (2) billion passengers annually. Therefore, it is necessary to study and plan for such a demand in the aviation industry (ATAG, 2007).

In South Africa, the demand for air transport services has been in an increase for the past decade. There has been a growth in passenger demand due to increasing physical activities and economic development of cities in different part of the country. Main activities were seen in provinces such as Gauteng, Eastern Cape and KwaZulu-Natal. These three provinces have more aviation activities than many provinces put together. The South Africa's major international airports are found in these provinces, that is, OR Tambo, Cape Town and King Shaka International airport, respectively (ACSA, 2013).

Air transport is the fastest mode of travel that connects different provinces within South Africa as well as connecting these provinces to the outside world. In South Africa, the domestic passenger movements have increased from 2734503 in 2000 to 26387228 in 2004. It rose from 26387228 in 2004 to 32951080 during the 2010 Soccer

\footnotetext{
${ }^{1}$ South African Government Information and Communications
} 
World Cup event, it went up to 85349475 in 2012 (ACSA, 2013).

Similarly, the demand for cargo by air has been on continuous increase for the period 2000 to 2012. All these indicate an increasing demand for all air transport services in the country. In order to accommodate air transport demand in South Africa, it is vital to plan for it. Thus, planning for air transport demand is of paramount importance and should form an integral part of the aviation industry (ACSA, 2013).

The objective of this study is to examine the patterns of the domestic air passenger demand in South Africa. The focus of the study is to establish the determinants of domestic air passenger demand in South Africa. The ability for any organisation to study the demand patterns of its services is very critical for its success. Hence, studying the demand patterns and the determinants of such demand in airports is very important and has serious implications in the airport planning processes (Demirsoy, 2012).

\section{Literature Review}

Air transport is plays a meaningful role in the social and economic developments of the world economy. This mode of travel is also very capital intensive and requires heavy investments. The air transport industry has been experiencing constant changes as a result of changing economic, political and transport security environment (Ba-Fail, Seraj and Jasimuddin, 2000).

In similar vein, airports play a significant part as enablers of social and economic activities. Their role in economic growth and tourism as well the development of the region and local economies is fundamental. Airports also enhance the connectivity of cities and countries as well as the global world. They also support the employment creation strategies of the country and play an essential role in business travel and tourism sectors of the economy $\left(\mathrm{UJ}^{2}, 2008\right)$.

In South Africa, there has been a continuous rise in the economic activities with the population rising to approximately 50 million inhabitants. Hence, the country is promising a high demand growth in air transport demand (DoT, 2009). In the past few decades, air travel was considered a luxury mode of travel where only few people in the country could afford to use air transport. However, things have changed with the economic improvements in the country which also changed the income levels of the South African population. Similarly, there has been a drastic change in the past few years due to the liberalisation of air transport industry and the introduction of the low cost carriers (LCC) such as Kulula.com, Mango and Comair. These airlines targeted lower income earners and offer them lucrative but affordable airfares. Thus, these arrangements increased the demand for air transport travel in the country (Demirsoy, 2012).

South Africa has experienced a substantial increase in income (gross domestic product). An increase in the South Africa's gross domestic product (GDP) has formed a back-bone for air transport growth in the country. The air transport growth was also intensified by the market deregulation through the bilateral and multilateral agreements with other countries. These at the same time led to the emergence of new private airlines, new business models (such as LCC) and rigorous infrastructure investments such as the construction of new airport (King Shaka) and the upgrading of existing airports (OR Tambo), with the intention to increase the capacity and accessibility to air transport services. The situation was also exacerbated by the hosting of the 2010 FIFA Soccer World Cup. This event has resulted in many activities and massive infrastructure investment in the period prior the world cup. This has also ensued in a rise in travel demand, particularly air travel (ACSA, 2012).

In general, the total domestic passenger enplanement in South African borders increased from 1.5 million in 1970 to 16.8 million in 2010. Figure 1 shows a continuous rise in demand for domestic air passenger enplanements for the period 1970 to 2010 (WorldBank, 2011).

\footnotetext{
2 University of Johannesburg
} 
Figure 1: Total domestic air passenger movements from 1970 t0 2010

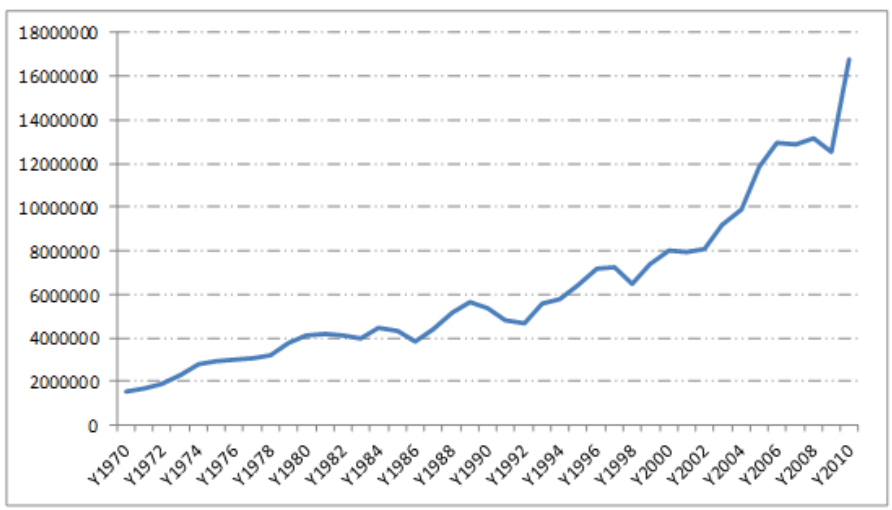

Data Source: WorldBank, 2011

In similar breath, the value of air freight transported increased from R56.8 million in 1970 to R1.1 billion in 2010 as indicated in Figure 2 below (WorldBank, 2011).

Figure 2: Domestic airfreight value in South Africa

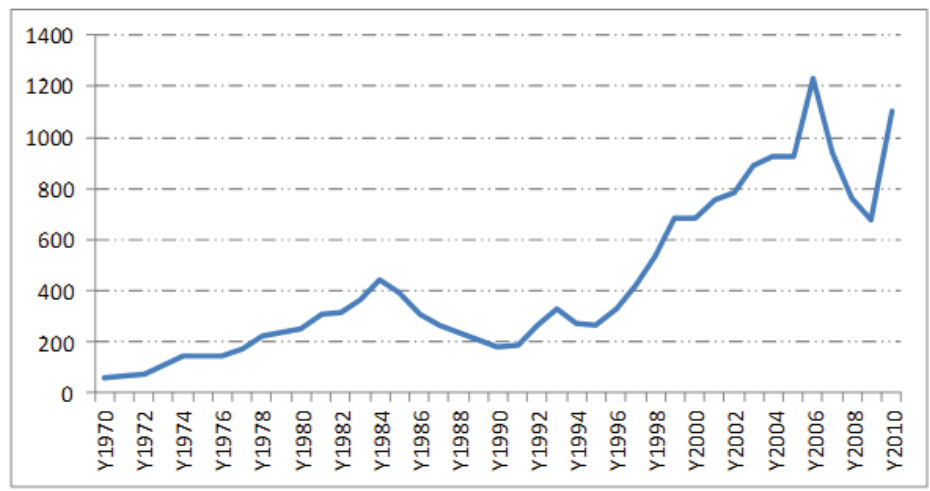

Data Source: WorldBank, 2011

The trends presented above (Figures $1 \& 2$ ) is a testimony that air transport demand will continue to rise in future as more people become willing to fly due to improved economic conditions. The continuous demand for air transport services implies that airports need to study the demand patterns in their territories and there is a need to investigate what constitute such demand (Demirsoy, 2012).

More than 97 per cent of air transport services in South Africa are provided by ACSA controlled airports. In 2012 calendar year alone, ACSA controlled airports handled over 35 million passengers and more than 500 aircraft landing from different destinations (ACSA, 2013). Approximately 90 per cent of commercial air passenger movements in the country is handled by three major international airports, i.e., OR Tambo, Cape Town and King Shaka. Figure 3 indicates that OR Tambo international airport alone handles a larger share of passenger movements with almost 19 million passengers, followed by Cape Town and King Shaka with approximated 9 million and 4.8 million passengers, respectively (UJ, 2008). 
Figure 3: Total Passenger Enplanement at ACSA controlled Airports

Data Source: ACSA, 2013

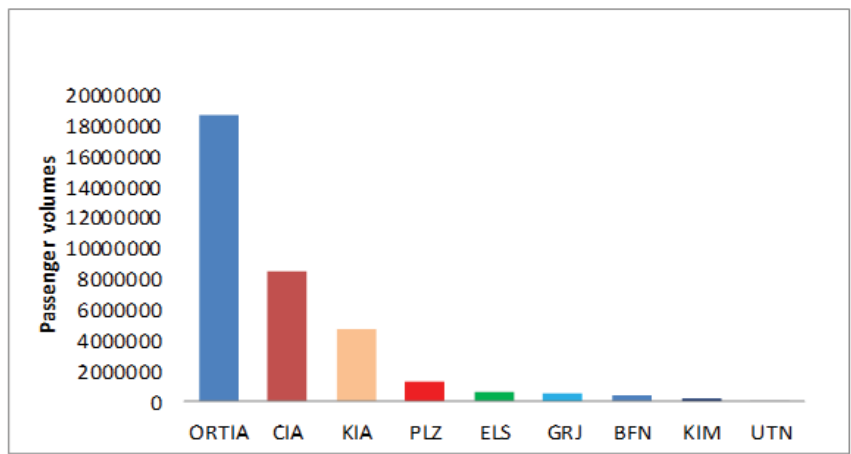

This trend has been recurring for a period of nine (9) years, i.e., 2004 to 2012. It is anticipated that these three airports will continue to dominate the South African air travel market (ACSA, 2013).

This study focused on the determinants of the domestic air passenger demand in South Africa. The literature reviewed indicates that there are many factors affecting the domestic air passenger demand. These basically include long range economic, social, demographic and political trends (Demirsoy, 2012). The task of this study is to determine the explanatory variables of econometric model for domestic air passenger demand in the Republic of South Africa. Reviewing and gathering information on the determinants of domestic air passenger demand helped to make the following list of economic and demographic variables:

- Income, Airfares, Population, Gross Domestic Product, Consumption, Expenditure, Crude Oil Prices and Employment Status

The demand function for this study will therefore be presented as:

$$
\operatorname{Pax}=\alpha+\beta_{1} \mathrm{Inc}+\beta_{2} \mathrm{Pop}+\beta_{3} \mathrm{GDP}+\beta_{4} \text { Cons }+\beta_{5} \operatorname{Exp}+\beta_{6} \mathrm{Fpr}+\beta_{7} \mathrm{Oil}+\beta_{8} \mathrm{Emp}+\varepsilon
$$

This is a multiple regression equation (Wensveen, 2012)

$$
\begin{array}{ll}
\text { Where, } & \\
\mathrm{Pax} & =\text { Passenger enplanement } \\
\mathrm{Inc}=\text { Income } & \\
\mathrm{Pop} & =\text { Population } \\
\mathrm{GDP} & =\text { Gross Domestic Product } \\
\mathrm{Cons} & =\text { Consumption } \\
\mathrm{Exp} & =\text { Expenditure } \\
\mathrm{Fpr}=\text { Airfares } & \\
\mathrm{Oil}=\text { Crude Oil Prices } \\
\mathrm{Emp} \quad=\text { Employment } \\
\mathrm{ar}=\text { Intercept } / \text { Constant }
\end{array}
$$

$\beta_{1}, \beta_{2}, \beta_{3}, \beta_{4}, \ldots \ldots \ldots \ldots, \beta z=$ Parameters (Coefficients of independent variables).

Taking their logarithms, we obtain:

$\log \mathrm{Pax}=\alpha+\beta_{1} \log \operatorname{lnc}+\beta_{2} \log \mathrm{Pop}+\beta_{3} \log \mathrm{GDP}+\beta_{4} \log \mathrm{Cons}+\beta_{5} \log \mathrm{Exp}+\beta_{6} \log F p r+\beta_{7} \log \mathrm{Oil}+\beta_{8} \log \mathrm{Emp}+\varepsilon$

This is a multiplicative demand function with constant elasticities over the complete range of values and these elasticities are given by the parameters $\beta_{1}, \beta_{2}, \beta_{3}, \beta_{4}, \ldots \ldots \ldots . . ., \beta_{z}$, which are estimated by the regression analysis (Aderamo, 2010).

\section{Discussion}

An effort was made to study the socio-economic factors influencing the domestic air passenger demand in the Republic 
of South Africa. The correlation matrix was used to study the relationship between various variables and to formulate a model with which the economic occurrences may be explored pragmatically. An econometric analysis was conducted through multiple regression models to explore the relationship between domestic air passenger demand and the selected socioeconomic variables. Table 1 below shows a correlation matrix whereby most variables are highly correlated (greater than 0.65 ). The problem with variables that are highly correlated is that they provide us with spurious result due to multicollinearity problem (Abed, Ba-Fai and Jasimuddin, 2001).

Table 1: Correlation matrix for all candidate explanatory variables and domestic passenger movements (1971 - 2012)

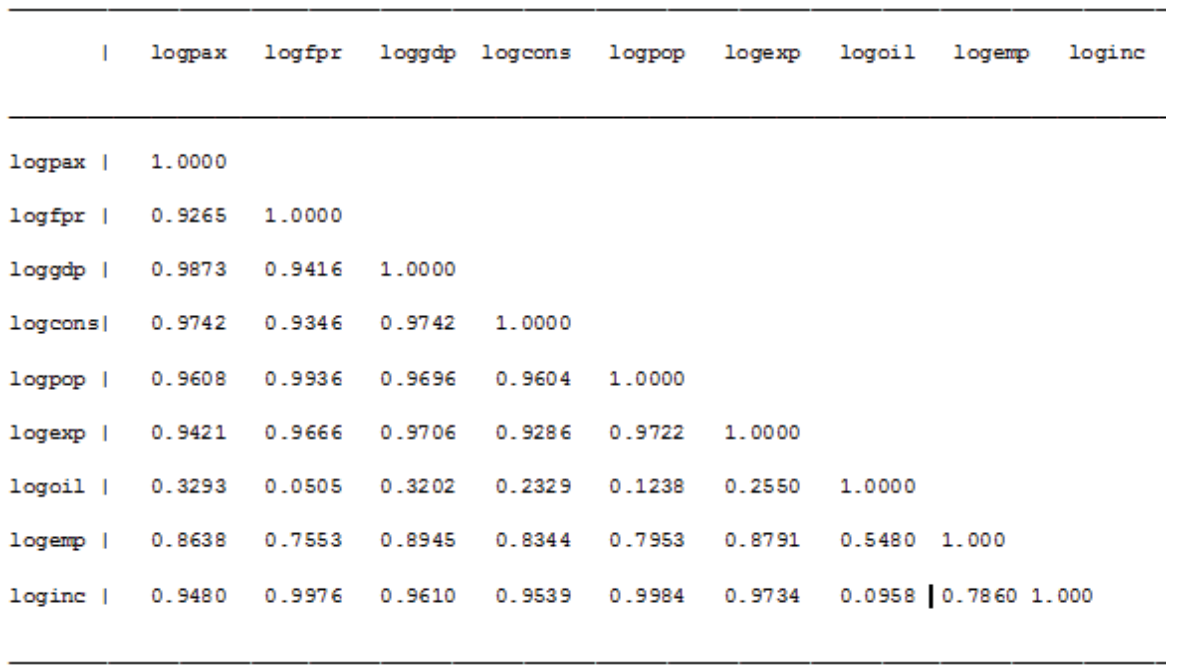

The correlation matrix illustrates a high correlation between gross domestic product and the air ticket price. It also shows high correlation between gross domestic product and household consumption. Again, consumption is highly correlated to the air ticket price. Similarly population is highly correlated to air ticket price, gross domestic product and household consumption. There is also a high correlation between expenditure and air ticket, gross domestic product, household consumption and population. Furthermore, employment is highly correlated to air ticket price, gross domestic product, household consumption, expenditure and population. Accordingly, these variables should be avoided in the model in order to avoid the multicollinearity problem and the tentative spurious results. So, the only variable relevant to domestic air travel in South Africa is the Brent crude oil.

The above findings gives logic in a sense that per capita income is derived from dividing the gross domestic product by population, hence the three variables will influence one another. Therefore, it makes sense not to use them together as explanatory variables in the same model. The same goes for population and the per capita income. In similar breath, there is high correlation between consumption and expenditure because total consumption is derived from the total expenditure excluding investment expenditure.

Based on the above discussions, the model that should represents the demand for domestic air passenger movements will be developed through a stepwise regression method for selecting explanatory variables. At each stage, an independent variable is deleted until prediction of the dependent variable does not improve (Abed et al, 2001). These models or regression equation was developed using Stata software. The Stata output shows the least-squares line of this model for domestic air passenger demand as follow:

$$
\text { Logpax = logpop - logfpr + logoil + logcons }
$$

Further results are presented in the following section of the study. 


\section{Results}

The results of multiple regression analysis are presented in two fold, in the first instance, all candidate determinants of domestic air passenger movements in South Africa is presented in Table 2 below:

Table 2: A Multiple Regression Analysis of all candidate determinants of domestic air passenger demand

\begin{tabular}{|c|c|c|c|c|c|c|c|c|}
\hline Source & I & \multicolumn{4}{|c|}{ df } & \multicolumn{2}{|r|}{ Number of obs $=$} & 42 \\
\hline & & & & & -- & & $F(8$, & 473.82 \\
\hline Model & I & 22.6796336 & 8 & 2.83 & 9542 & & Prob > F & 0.0000 \\
\hline Residual & I & .197443822 & 33 & .0059 & 3146 & & R-squared & 0.9914 \\
\hline & & & & & --- & & Adj $R$-squared = & 0.9893 \\
\hline Total & I & 22.8770775 & 41 & .5579 & 7499 & & Root MSE & $=.07735$ \\
\hline logpax & I & Coef. & Std. & Err. & $t$ & $P>|t|$ & [95\% Conf. & Interval] \\
\hline $\operatorname{logfpr}$ & I & -.7516525 & .436 & 5178 & -1.72 & 0.094 & -1.639063 & .1357582 \\
\hline loggdp & I & .24297 & .6494 & 256 & 0.37 & 0.711 & -1.078296 & 1.564236 \\
\hline $\operatorname{logcons}$ & I & .1105803 & .2488 & 006 & 0.44 & 0.660 & -.3956083 & .6167688 \\
\hline logpop & I & 5.390471 & 1.642 & 632 & 3.28 & 0.002 & 2.048512 & 8.73243 \\
\hline logexp & I & -.6971975 & .5028 & 474 & -1.39 & 0.175 & -1.720248 & .3258533 \\
\hline logoil & I & .1932653 & .0586 & 5649 & 3.29 & 0.002 & .0739107 & .31262 \\
\hline logemp & I & .2305604 & .2725 & 662 & 0.85 & 0.404 & -.3239797 & .7851004 \\
\hline loginc & I & .2305236 & .4793 & 346 & 0.48 & 0.634 & -.7446901 & 1.205737 \\
\hline _cons & I & -39.39943 & 14.89 & 287 & -2.65 & 0.012 & -69.6992 & -9.099658 \\
\hline
\end{tabular}

The results of multiple regression shown in Table 2 indicate that there is a problem of multicollinearity. This problem may be brought by different reasons such as having an array of independent variables in the same model. Some of the independent variables correlate with each other and as a result, provide us with spurious results. In this case, many variables were used to model the passenger demand at the same time in the same model, leading to a situation whereby most variable were highly correlated. Hence, we have insignificant $p$-values for majority of the independent variable while the overall $\mathrm{F}$ statistics and adjusted $\mathrm{R}^{2}$ were very significant.

To alleviate the problem of multicollinearity and avoid spurious regression results, the stepwise regression method was employed for the study in order to reduce the number of variables and building a solid model for the study. The study began by eliminating variables that were mostly insignificant.

Based on the above discussion, we observed that population (logpop), crude oil prices (logoil), household consumption and airfares (logfpr) were the most significant variables that influences the demand for domestic air passenger travel in South Africa. The Stata for data analysis was then used to explore the relationship between these variables and the domestic air passenger demand (Abed, 2001). The regression analysis of these variables is presented in Table 3 below. 
Table 3: Regression Analysis for the most significant variable

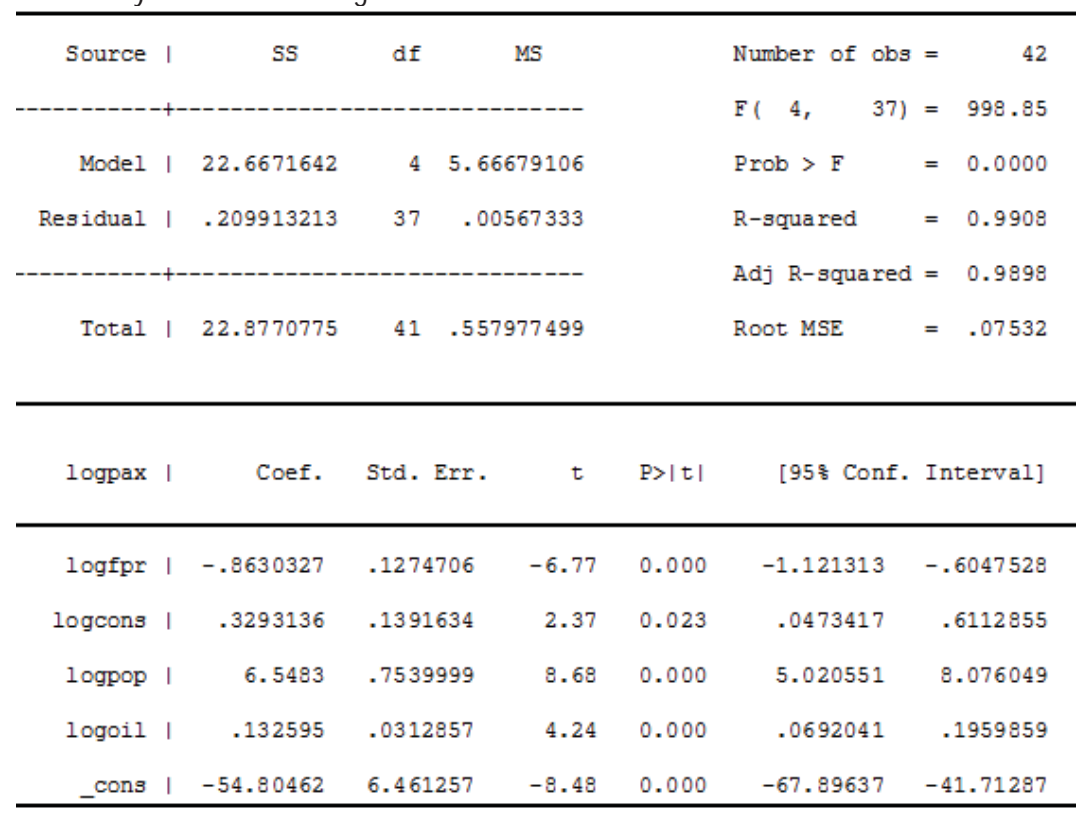

The Stata results presented in Table 3 indicate that the price of air ticket has a negative effect on the domestic air passenger travel demand, ceteris paribus. Thus, a 1 per cent increase in the airfares will result in an average of 0.863 million decrease in the demand for domestic air passenger travel.

On the other hand, household consumption, population and crude oil prices have positive effects on domestic air passenger demand, holding other things constant. As population goes up by 1 per cent, on the average the demand for air travel will also go up by 6.548 million passengers. In similar vein, as the household consumption increase by 1 per cent will be met by a corresponding increase of 0.329 million domestic air passengers. Likewise, an increase of oil price by 1 per cent will result in an average increase in demand for domestic air passenger travel by 0.133 million.

Furthermore, the $p$-values of all independent variables are significant at 5 per cent level of significance. Thus, at 5 per cent level of significant the $p$-values all variables are significant (i.e., $0.0000>0.05$ ), consumption is also significant at 0.023 which is also greater than 0.05 .

The two-tailed t-test can be used to test whether the null hypothesis stands against the alternative hypothesis that the coefficients for population, airfares, household consumption and prices of Brent crude oil are different from zero. The degrees of freedom are 37, which are obtained by subtracting the number of parameters estimated from number of observation $(n=22)$. At this instance, the numbers of parameters estimated are 5 . Again, the t-values presented in Table 3 shows that each partial regression is significant (i.e. significantly different from zero) at 5 per cent level of significance.

Similarly, the $\mathrm{R}^{2}$ is 0.9908 and the adjusted $\mathrm{R}^{2}$ is also 0.9898 , which implies that the domestic air passenger demand is 99 per cent explained by the combination of population, airfares, consumption and oil prices.

Therefore, our model for estimating the domestic air passenger demand will be given as:

$$
\text { logpax }=-54.80462+6.5483 \text { logpop }-0.8630327 \text { logfpr + 0.3293136locons + 0.132595logoil }
$$

\section{Conclusion}

This paper provides a comprehensive narrative of the stages followed for the development of econometric modelling of the domestic air passenger travel in the Republic of South Africa. The econometric model was utilised to analyse the demand for air passenger movement through the establishment of relationship between candidate independent variables and the dependent variable (domestic air passenger demand). It was then established that only four variables (i.e., population, airfares, oil prices and the level of household consumption) are the most significant and main determinants of 
domestic air passenger demand. This model is also very good in terms of Goodness of Fit measures and does not suffer from multicollinearity.

Based on the domestic air passenger demand analysis through the proposed model, the airlines, airports, civil aviation authorities and Department of transport, academics and many other aviation stakeholders can develop their plans. The study would also contribute towards policy guidelines in studying airports planning and expansion of facilities in their regions.

\section{References}

Abed, S.Y., Ba-Fail, A.O., and Jasimuddin, S.M. (2001). An Econometric Analysis of International Air Travel Demand in Saudi Arabia. Industrial Engineering Department. King Abdulaziz University. Jeddah. Saudi Arabia. Journal of Air Transport Management vol. no. 7 (2001) $143-148$.

ACSA. (2012). Economic Impact Study on all the airports managed by ACSA. Airports Company South Africa. South Africa. Johannesburg.

ACSA. (2013). Statistics on passenger and aircraft movements received from ACSA. Airports Company South Africa. South Africa. Johannesburg.

Aderamo, A.J. (2010). Demand for Air Transport in Nigeria. Department of Geography. University of Ilorin. Ilorin. Nigeria. Journal of Economics, vol. 1 (1): $23-31$ (2010).

ATAG. (2007). The Economic and Social Benefits of Air Transport. Air Transport Action Group. Switzerland, Geneva.

Ba-fail, A.O., Abed, S.Y., and Jasimuddin, S.M. (2000). The determinants of domestic air travel demand in the Kingdom of South Arabia. Journal of Air Transportation World Wide, 5(2), 72 -86.

Demirsoy, C. (2012). Analysis of Stimulated Domestic Air Transport Demand in Turkey. What are the drivers? Masters Research Thesis. School of Economics. Erasmus University. Rottedam.

Gujarati, D.N., and Porter, D.C. (2010). Basic Econometrics. 5th edition. MaGraw-Hill International Edition. Singapore.

SAGCIS. (2013). Internet source accessed on South African Government Communication and Information System at www.gov.za/transport.htm.

University of Johannesburg. (2008). An overview of the Airport Industry In South Africa and Determinants of the Economic Impacts of O.R. Tambo International Airport, Cape Town International Airport and Durban International Airport. $1^{\text {st }}$ Draft. 2008. Johannesburg, South Africa.

Wells, A.T. (2003). Air Transportation. A Management Perspective. $2^{\text {nd }}$ edition. Wadsworth. USA

Wensveen, J.G. (2012). Air Transportation. A Management Perspective. $7^{\text {th }}$ edition. Ashgate Publishing. Burlington. USA

Worldbank, 2012. World Bank Data accessed on the internet at www.worldbank.org/country/South Africa. Accessed on the 10 th December 2012. 